\title{
Molecular characteristics of urothelial neoplasms in children and young adults: a subset of tumors from young patients harbors chromosomal abnormalities but not FGFR3 or TP53 gene mutations
}

Sean R Williamson ${ }^{1}$, Mingsheng Wang ${ }^{2}$, Rodolfo Montironi ${ }^{3}$, John N Eble ${ }^{2}$, Antonio Lopez-Beltran ${ }^{4}$, Shaobo Zhang ${ }^{2}$, Rong Fan ${ }^{2}$, Lisha Wang ${ }^{5}$, Adeboye O Osunkoya ${ }^{6}$, Michael $\mathrm{O} \mathrm{Koch}^{7}$ and Liang Cheng ${ }^{2,7}$

${ }^{1}$ Department of Pathology and Laboratory Medicine, Henry Ford Hospital, Detroit, MI, USA; ${ }^{2}$ Department of Pathology and Laboratory Medicine, Indiana University School of Medicine, Indianapolis, IN, USA; ${ }^{3}$ Institute of Pathological Anatomy and Histopathology, School of Medicine, Polytechnic University of the Marche Region (Ancona), United Hospitals, Ancona, Italy; ${ }^{4}$ Department of Pathology, Cordoba University, Cordoba, Spain; ${ }^{5}$ Department of Pathology, Fudan University Shanghai Cancer Center, Shanghai, China; ${ }^{6}$ Department of Pathology, Emory University, Atlanta, GA, USA and ${ }^{7}$ Department of Urology, Indiana University School of Medicine, Indianapolis, IN, USA

\begin{abstract}
Urothelial neoplasms in children and young adult patients are rare and hypothesized to have a lower rate of recurrence and progression than those of older adults. Because of their rarity, data regarding molecular abnormalities in these tumors are limited. We studied molecular characteristics of urothelial neoplasms from patients under age 30 years using UroVysion fluorescence in situ hybridization (chromosomes 3, 7, 17, and 9p21) and DNA mutational analysis for the FGFR3 and TP53 genes. Seventeen tumors were identified in patients 6-26 years of age, including low-grade papillary urothelial carcinoma $(n=10)$, high-grade papillary urothelial carcinoma $(n=5)$, urothelial papilloma $(n=1)$, and papillary urothelial neoplasm of low malignant potential $(n=1)$. No tumor demonstrated mutation of FGFR3 or TP53. Chromosomal abnormalities were detected only in patients aged $\geq 19$ years: two low-grade urothelial carcinomas had loss of 9p21 as a sole chromosomal abnormality and three high-grade urothelial carcinomas had other or multiple chromosomal abnormalities. Under age 19 years, no tumor showed molecular abnormalities with either method (five low-grade papillary urothelial carcinomas and one each of high-grade papillary urothelial carcinoma, papillary urothelial neoplasm of low malignant potential, and urothelial papilloma). Our results support the idea that mutations of the FGFR3 and TP53 genes are rare or absent in urothelial neoplasms of young patients. In contrast, chromosomal abnormalities detected by UroVysion fluorescence in situ hybridization are sometimes present in patients above 19-20 years of age. This finding supports the recently proposed hypothesis that an age of 19-20 years separates distinct molecular pathways of urothelial carcinogenesis.

Modern Pathology (2014) 27, 1540-1548; doi:10.1038/modpathol.2014.48; published online 18 April 2014
\end{abstract}

Keywords: fibroblast growth factor receptor 3 (FGFR3); fluorescence in situ hybridization; molecular genetics; TP53 mutation; urinary bladder; urothelial carcinomas

Correspondence: Professor L Cheng, MD, Department of Pathology and Laboratory Medicine, Indiana University School of Medicine, 350 West 11th Street, IU Health Pathology Laboratory Room 4010, Indianapolis, IN 46202, USA.

E-mail: liang_cheng@yahoo.com

Received 27 August 2013; revised 25 January 2014; accepted 26 January 2014; published online 18 April 2014
In children and young adults, urothelial neoplasms such as urothelial carcinoma are rare, in contrast with older adults, particularly men, in whom the urinary bladder is among the most common sites for development of a new cancer. ${ }^{1-3}$ When urothelial carcinoma does occur in the pediatric and young adult population, it is generally thought that the 
biologic behavior differs, including a lower rate of recurrence and progression. ${ }^{2,4-9}$ Because of the rarity of urothelial neoplasms in these patients, data regarding the molecular alterations of urothelial carcinoma in this age group are limited. Nonetheless, there is emerging evidence to indicate that the characteristic molecular alterations of urothelial carcinomas of older adults are either absent or uncommon in young patients. ${ }^{10-12}$ In order to better understand the pathogenesis of urothelial neoplasms in young patients and compare and contrast them with those of older patients, we assessed molecular features in a series of 17 tumors from children and young adults (under age 30 years) using fluorescence in situ hybridization with the UroVysion probe set and DNA sequencing mutational analysis for the FGFR3 and TP53 genes.

\section{Materials and methods}

\section{Specimens}

Formalin-fixed and paraffin-embedded tissue blocks from urothelial neoplasms of patients under 30 years of age were retrieved via search of the in-house and consultation files of the contributing authors to include lesions originally diagnosed as urothelial papilloma, papillary urothelial neoplasm of low malignant potential (PUNLMP), papillary urothelial carcinoma (any grade), urothelial carcinoma in situ, or invasive (papillary and nonpapillary) urothelial carcinoma. Hematoxylin and eosin-stained microscopic slides were reviewed and neoplasms were reclassified according to the World Health Organization and International Society of Urologic Pathology classification system. ${ }^{13}$ Nonneoplastic urothelial proliferations, such as polypoid or papillary cystitis, and putative precursor lesions, such as urothelial hyperplasia, were not studied. Tumors developing in the setting of urinary bladder augmentation, in which segments of the gastrointestinal tract are utilized in reconstruction of the urinary bladder, were also excluded from the study. ${ }^{14-16}$

\section{Fluorescence In Situ Hybridization}

Unstained sections were prepared from the available tissue blocks and were deparaffinized with xylene for fluorescence in situ hybridization using the UroVysion probe set, using the methods previously described. ${ }^{17}$ For this method, the slides were treated with absolute ethanol, and then air dried and boiled in a glass staining jar with $1 \times$ citrate buffer $(\mathrm{pH}$ 6.0) (Zymed, CA, USA) within a beaker filled with distilled water on a hot block for $10 \mathrm{~min}$. Slides were washed with distilled water and transferred to $2 \times$ sodium citrate buffer (SSC) for $5 \mathrm{~min}$. The slides were air dried and digested with $0.75 \mathrm{ml}$ pepsin ( $5 \mathrm{mg} / \mathrm{ml}$ in $0.01 \mathrm{~N} \mathrm{HCl}$ with $0.9 \% \mathrm{NaCl}$; Sigma, St Louis, MO, USA) at $37^{\circ} \mathrm{C}$ for $40 \mathrm{~min}$. The slides were then washed with distilled water and $2 \times$ SSC, followed by air drying. Chromosome enumeration probes (CEPs) for chromosomes 3, 7, and 17, and the locus-specific indicator (LSI) probe for 9p21 were labeled with fluorophores. CEP3, CEP7, and CEP17 probes were labeled with Spectrum Red, Spectrum Green, and Spectrum Aqua, respectively. LSI p16 (9p21) was labeled with Spectrum Gold (Vysis, Downers Grove, IL, USA). The probes were diluted 1:10 with tDenHyb2 (Insitus, Albuquerque, NM, USA). To each slide, $5 \mu$ l of diluted probes was added in reduced light conditions. The slides were then covered with a $22 \times 22$ coverslip, sealed with rubber cement, and put into an opaque plastic box wrapped with aluminum foil. The slides were denatured at $83^{\circ} \mathrm{C}$ for $12 \mathrm{~min}$ and hybridized at $37^{\circ} \mathrm{C}$ overnight. After hybridization, the slides were washed and counterstained with $10 \mu \mathrm{l}$ DAPI (Insitus) and sealed with a $50 \times 22$ coverslip.

The stained slides were observed and documented using MetaSystem software (Belmont, MA, USA) under $100 \times$ oil objective using filters: SP-100 for DAPI, FITC MF-101 for Spectrum Green, Gold 31003 for Spectrum Gold, Aqua 31036V2 for Spectrum Aqua, and Texas Red Sp103 for Spectrum Red signals. Five sequential focus stacks with $0.4 \mu \mathrm{m}$ intervals were acquired and integrated into a single image to reduce thickness-related artifacts.

For each case, 200 nuclei were counted. Each cell was simultaneously analyzed for the signals of chromosomes 3, 7, 17, and 9p21. Chromosomal gain or loss was defined based on the Gaussian model and relative to normal controls. As previously reported, the percentage of cells with chromosomal abnormalities in formalin-fixed, paraffin-embedded tissue sections from urothelial malignancies are typically high, with abnormalities detected in the majority of cells. ${ }^{18}$ In contrast, normal urothelium from patients without a known bladder malignancy typically exhibits only rare cells with numerical chromosomal abnormalities, potentially because of section truncation artifact, unrecognized overlapping nuclei, and rare normal cells in G2 or M phase of the cell cycle. ${ }^{19,20}$ Therefore, cutoff values for an abnormal result were set at the mean plus 3 standard deviation of the number of disomic cells in control individuals. The mean plus 3 standard deviation represents a specificity of 99.9\%. Any tumor cases with a score beyond the cutoff value were considered to have either a gain or a loss of the designated chromosome(s).

\section{Mutational Analysis}

Mutational analysis of the FGFR3 and TP53 genes was performed using methods similar to those previously described, and was compared with previously published rates of mutations of these genes in urothelial carcinomas of older adults. ${ }^{21-30}$ For this technique, laser-assisted microdissection of 

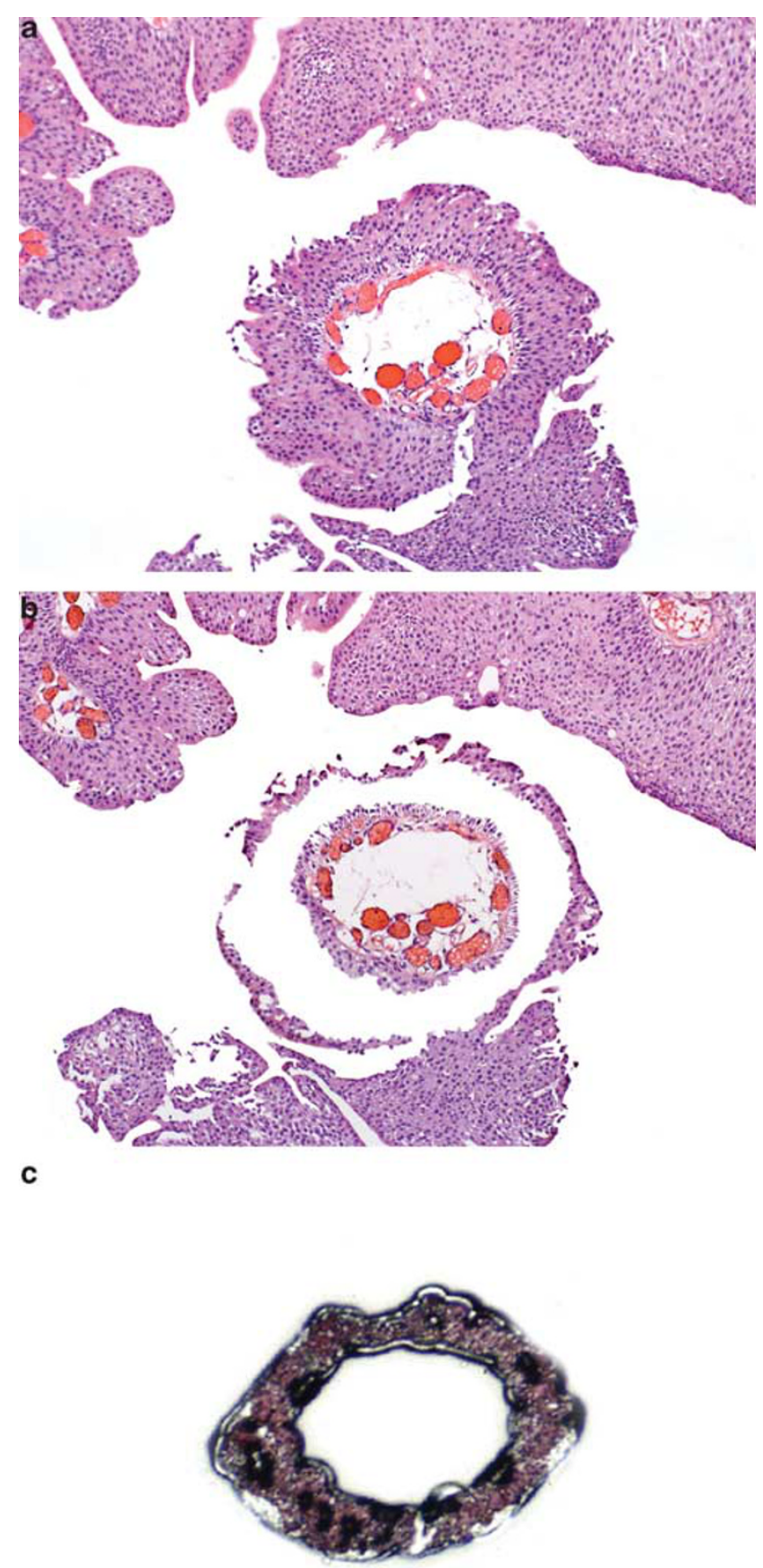

Figure 1 Tumor tissue for DNA mutational analysis of the FGFR3 and TP53 genes was collected using laser capture microdissection from formalin-fixed, paraffin-embedded tissue blocks containing urothelial neoplasms from young patients. (a) Hematoxylin and eosin-stained sections were examined to identify the neoplastic cells for laser capture microdissection. After microdissection, the neoplastic epithelial cells (b) have been selectively removed and the enriched sample (c) can be utilized for DNA mutational analysis.

the tumor tissues was performed (Figure 1) on lightly hematoxylin and eosin-stained sections using a PixCell II Laser Capture Microdissection System (Arcturus Engineering, Mountain View, CA, USA). ${ }^{31,32}$ Approximately $600-1000$ cells of each tumor were microdissected from the $4 \mu \mathrm{m}$ histological sections. Microdissected normal tissue from the same patient served as a control. The dissected tissue was incubated in $50 \mathrm{ml}$ of digesting buffer containing $10 \mathrm{mM}$ Tris-HCl, $1 \mathrm{mM}$ EDTA, $1 \%$ Tween-20, and $5 \mathrm{mg} / \mathrm{ml}$ of proteinase $\mathrm{K}(\mathrm{pH} 8.3)$ at $37^{\circ} \mathrm{C}$ overnight. The samples were boiled for $10 \mathrm{~min}$ to inactivate proteinase K. The genomic DNA from each sample was dissolved in $30 \mathrm{ml}$ of dd $\mathrm{H} 2 \mathrm{O}$ after phenol-chloroform extraction (phenol/chloroform/ isoamyl alcohol 1/4 25:24:1).

For the FGFR3 gene, exons 7, 10, and 15 were amplified by polymerase chain reaction (PCR) using previously established primers. ${ }^{21,25,33,34}$ PCR was performed with $3 \mathrm{ml}$ of isolated genomic DNA in a final volume of $50 \mathrm{ml}$ containing $2.3 \mathrm{mM} \mathrm{MgCl}_{2}$, $10 \mathrm{mM}$ Tris-HCl (pH 8.3), $50 \mathrm{mM} \mathrm{KCl,} 2 \mathrm{mM}$ deoxynucleotide triphosphates, $2 \mathrm{mM}$ each primer, and $2 \mathrm{U}$ Taq DNA polymerase (Bio-Rad, Hercules, CA, USA). Each PCR protocol had an initial denaturing step of $95{ }^{\circ} \mathrm{C}$ for $5 \mathrm{~min}$, followed by 40 cycles of: $95^{\circ} \mathrm{C}$ for $30 \mathrm{~s}, 55^{\circ} \mathrm{C}$ (for exons 7 and 15) or $58{ }^{\circ} \mathrm{C}$ (for exon 10) for $30 \mathrm{~s}$, and $72{ }^{\circ} \mathrm{C}$ for $30 \mathrm{~s}$. There was a single final extension step at $72{ }^{\circ} \mathrm{C}$ for $7 \mathrm{~min}$. The PCR products were purified using the QIAquick PCR Purification kit (Qiagen Sciences, Germantown, MD, USA). DNA concentration of PCR products was measured and adjusted to $20 \mathrm{ng}$ per $\mu \mathrm{l}$. Sequencing of the purified PCR product was then performed using an ABI Prism 3100 Genetic Analyzer (Applied Biosystems, Foster City, CA, USA).

For the TP53 gene, DNA from exons 5, 7, and 8 was similarly amplified by PCR using previously established primers. ${ }^{29,35,36}$ PCR was performed with $3 \mathrm{ml}$ of isolated genomic DNA in a final volume of $50 \mathrm{ml}$ containing $2.3 \mathrm{mM} \mathrm{MgCl}_{2}, 10 \mathrm{mM}$ Tris-HCl ( $\mathrm{pH}$ 8.3), $50 \mathrm{mM} \mathrm{KCl}, 2 \mathrm{mM}$ deoxynucleotide triphosphates, $2 \mathrm{mM}$ each primer, and $2 \mathrm{U}$ Taq DNA polymerase (Bio-Rad). Each PCR protocol had an initial denaturing step of $95^{\circ} \mathrm{C}$ for $5 \mathrm{~min}$, followed by 40 cycles of $95^{\circ} \mathrm{C}$ for $30 \mathrm{~s}, 55^{\circ} \mathrm{C}$ for $30 \mathrm{~s}$, and $72{ }^{\circ} \mathrm{C}$ for $30 \mathrm{~s}$, followed by a single final extension step at $72{ }^{\circ} \mathrm{C}$ for $7 \mathrm{~min}$. The PCR products were purified by QIAquick PCR Purification kit (Qiagen Sciences). DNA concentration of the PCR products was measured and adjusted to $20 \mathrm{ng}$ per $\mu \mathrm{l}$. The purified PCR product was sequenced using an ABI Prism 3100 Genetic Analyzer.

\section{Results}

\section{Patients and Tumors}

Seventeen urothelial neoplasms were retrieved, all of which were initially removed by transurethral resection. The patients' ages ranged from 6 to 26 years (median 19). Twelve patients were male and 5 were female (M/F 2.4:1) After reassessment of histologic classification and grade, the tumors included low-grade papillary noninvasive urothelial 

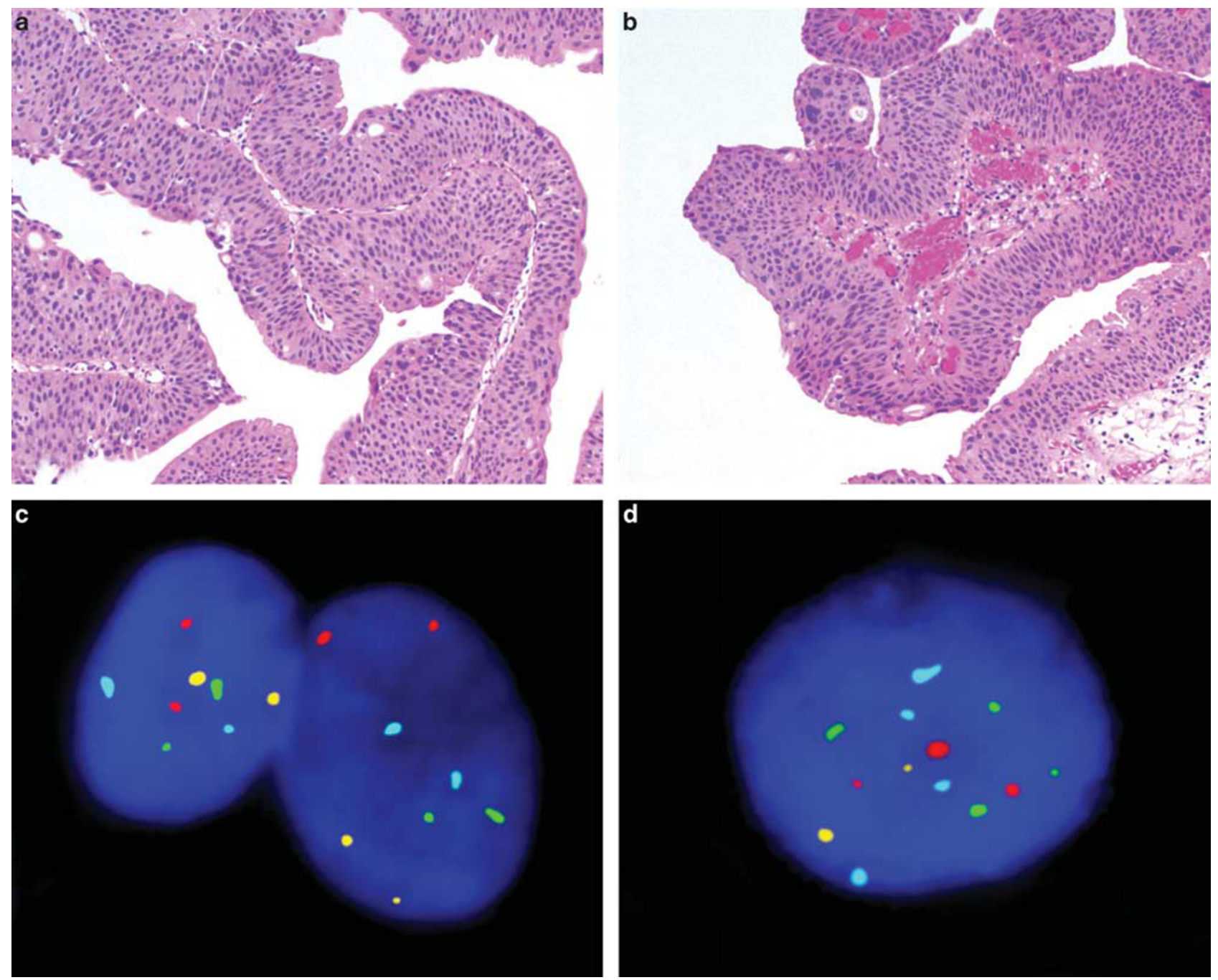

Figure 2 Results of UroVysion fluorescence in situ hybridization in urothelial neoplasms from young patients: microscopically, lowgrade papillary urothelial carcinomas (a) were composed of papillary structures lined by urothelial cells with a limited degree of cytologic atypia and disorganized architecture. In contrast, high-grade urothelial carcinomas (b) exhibited more pronounced cytologic atypia, including scattered markedly enlarged, hyperchromatic, and irregularly shaped nuclei. Using fluorescence in situ hybridization, most tumors showed a wild-type or disomic pattern for each of the studied chromosomes (c), as evidenced by two red, green, aqua, and gold signals in each tumor cell nucleus. A subset of tumors from patients $\geq 19$ years of age showed chromosomal abnormalities with this technique, such as gains of chromosomes 3, 7, and 17 (d), evidenced by more than two red, green, and aqua signals in the tumor cell nuclei (same high-grade tumor as depicted in b).

carcinoma (10 tumors, 59\%; Figure 2a), high-grade papillary urothelial carcinoma (5 tumors, 29\%; Figure 2b), PUNLMP (1 tumor, 6\%), and urothelial papilloma (1 tumor, 6\%). One patient (19 years of age) had a high-grade papillary urothelial carcinoma with an invasive component and was found to have deep muscularis propria invasion (pathologic stage pT2b) with lymph node metastases in a subsequent resection specimen.

\section{Fluorescence In Situ Hybridization}

Using fluorescence in situ hybridization with the UroVysion probe set for chromosomes 3, 7, 17, and 9p21, the majority of tumors showed a wild-type or disomic pattern for each of the studied chromosomes and the 9p21 locus (12 of 17 tumors, $71 \%$; Figure 2c). Two low-grade papillary urothelial carcinomas had loss of chromosomal locus 9p21 as the only detected abnormality (Table 1), accounting for $12 \%$ of all tumors studied and $20 \%$ of the group of low-grade papillary urothelial carcinomas. Three high-grade papillary urothelial carcinomas (of 5 total high-grade tumors) had other chromosomal abnormalities or multiple abnormalities, including: loss of chromosome 7 (1 patient); gain of chromosomes 3, 7, and 17 (1 patient; Figure $2 \mathrm{~d}$ ); and loss of chromosome 7 and the 9p21 locus (1 patient; Table 1). Loss of 9p21 as a sole abnormality occurred only in low-grade tumors $(n=2)$, whereas other abnormalities occurred only in high-grade tumors 
Table 1 Molecular characteristics of urothelial neoplasms of young patients

\begin{tabular}{|c|c|c|c|c|c|c|c|c|c|c|c|c|c|c|}
\hline & Gender & Age & Classification & CEP3 & CEP7 & $9 p 21$ & CEP17 & Overall & Exon 7 & Exon10 & Exon 15 & Exon 5 & Exon7 & Exon 8 \\
\hline 1 & $\mathrm{M}$ & 26 & HG & Negative & Negative & Negative & Negative & Negative & No & No & No & No & No & No \\
\hline 2 & M & 26 & HG & Gain & Gain & Negative & Gain & Positive & No & No & No & No & No & No \\
\hline 3 & $\mathrm{~F}$ & 25 & LG & Negative & Negative & Loss & Negative & Positive & No & No & No & No & No & No \\
\hline 4 & $\mathrm{M}$ & 24 & HG & Negative & Loss & Loss & Negative & Positive & No & No & No & No & No & No \\
\hline 5 & $\mathrm{M}$ & 24 & LG & Negative & Negative & Loss & Negative & Positive & No & No & No & No & No & No \\
\hline 6 & $\mathrm{M}$ & 23 & LG & Negative & Negative & Negative & Negative & Negative & No & No & No & No & No & No \\
\hline 7 & $\mathrm{M}$ & 22 & LG & Negative & Negative & Negative & Negative & Negative & No & No & No & No & No & No \\
\hline 8 & $\mathrm{M}$ & 20 & LG & Negative & Negative & Negative & Negative & Negative & No & No & No & No & No & No \\
\hline 9 & $\mathrm{M}$ & 19 & HG & Negative & Gain & Negative & Negative & Positive & No & No & No & No & No & No \\
\hline 10 & $\mathrm{~F}$ & 18 & LG & Negative & Negative & Negative & Negative & Negative & No & No & No & No & No & No \\
\hline 11 & $\mathrm{M}$ & 18 & LG & Negative & Negative & Negative & Negative & Negative & No & No & No & No & No & No \\
\hline 12 & $\mathrm{~F}$ & 18 & HG & Negative & Negative & Negative & Negative & Negative & No & No & No & No & No & No \\
\hline 13 & $\mathrm{~F}$ & 18 & LG & Negative & Negative & Negative & Negative & Negative & No & No & No & No & No & No \\
\hline 14 & M & 12 & Papilloma & Negative & Negative & Negative & Negative & Negative & No & No & No & No & No & No \\
\hline 15 & M & 12 & PUNLMP & Negative & Negative & Negative & Negative & Negative & No & No & No & No & No & No \\
\hline 16 & $\mathrm{~F}$ & 9 & LG & Negative & Negative & Negative & Negative & Negative & No & No & No & No & No & No \\
\hline 17 & M & 6 & LG & Negative & Negative & Negative & Negative & Negative & No & No & No & No & No & No \\
\hline
\end{tabular}

Abbreviations: M, male; F, female; HG, high-grade urothelial carcinoma; LG, low-grade urothelial carcinoma; PUNLMP, papillary urothelial neoplasm of low malignant potential; CEP, chromosome enumeration probe; No, no mutation identified.

a

Exon 7, Codon $247-258$

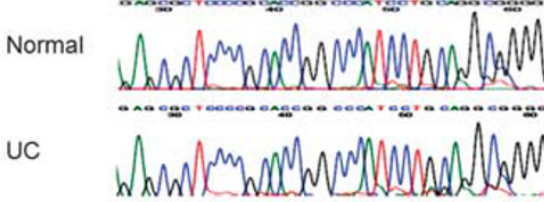

Exon 10, Codon 396-407

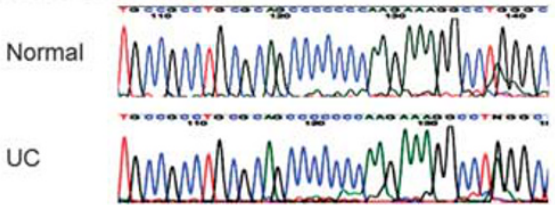

Exon 15, Codon 648-659

Normal

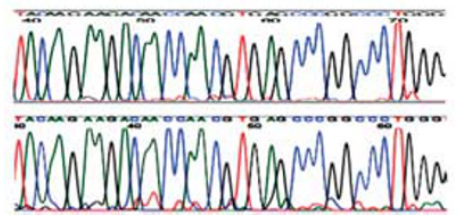

b

TP53 Sequencing Chromatograms

Exon 5, Codon 175-186

Normal

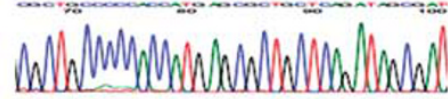

UC

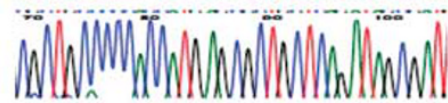

Exon 7, Codon 245-256

Normal

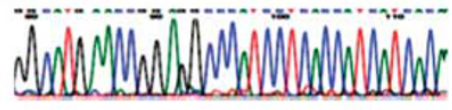

UC

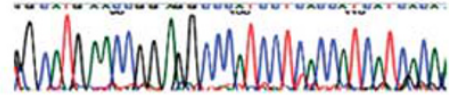

Exon 8, Codon 268-279

Normal

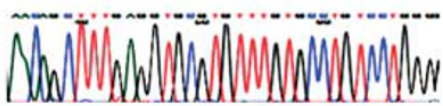

UC

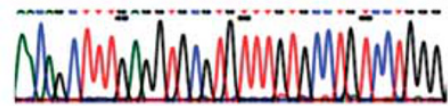

Figure 3 DNA sequencing chromatograms from the FGFR3 (a) and TP53 (b) genes did not reveal mutations at the studied exons in the neoplastic tissue from any tumor (bottom rows), when compared with normal control tissue (top rows). UC, urothelial carcinoma; normal, normal control tissue.

$(n=3)$. All tumors from patients under 19 years of age exhibited no abnormalities (five low-grade papillary urothelial carcinomas, one high-grade papillary urothelial carcinoma, one urothelial papilloma, and one PUNLMP).

\section{DNA Mutational Analysis}

Using DNA sequencing mutational analysis for the FGFR3 and TP53 genes, no tumor showed mutation of either gene. Studied exons included 7, 10, and 15 for FGFR3 and 5, 7, and 8 for TP53 (Figure 3 and Table 1).

\section{Discussion}

In children and young adults, the development of urothelial neoplasms such as urothelial carcinoma is rare, particularly at the youngest end of this age group. ${ }^{4-7,37}$ As such, the etiology and pathogenesis 
of these tumors are not well understood. ${ }^{2}$ In general, it appears that most urothelial carcinomas in these patients are of low grade, with infrequent recurrence and more indolent behavior when compared with those of adults; $4,5,9,38$ however, other data suggest that recurrence and invasion do sometimes occur. ${ }^{4,7-9,37,39}$ Through the first four decades of life, the incidence of urothelial carcinoma appears to increase slightly overall, although it remains rare. ${ }^{2}$ As such, understanding of the molecular pathogenesis of tumors in this setting is quite limited, in contrast to tumors of older adults, in whom molecular pathways of urothelial tumorigenesis have been more thoroughly characterized. ${ }^{10-12,23,40}$ To date, it appears that the typical molecular abnormalities of urothelial neoplasms of older patients are often lacking in tumors of children and young adults. ${ }^{10,11}$ To better understand the pathogenesis of tumors that occur in this patient population, we assessed molecular features of urothelial neoplasms from patients under age 30 years using UroVysion fluorescence in situ hybridization and mutational analysis for the FGFR3 and TP53 genes.

Urothelial carcinoma is characteristically a disease of older patients, preferentially affecting men. ${ }^{23}$ In older adult patients, a variety of risk factors such as cigarette smoking and exposure to other carcinogens, such as those used in the dye, rubber, textile, and chemical industries, have been well established. ${ }^{41,42}$ In children and young adults, however, understanding of the etiology and pathogenesis of urothelial tumors remains more elusive. ${ }^{2}$ An association with cigarette smoking has been noted in some patients; ${ }^{4}$ however, in others no history of exposures is known. ${ }^{6}$ Combined with the substantially shorter duration of exposure for a young patient, these risk factors seem unlikely to account entirely for the occurrence of urothelial carcinoma in this setting. Similarly, hereditary tumor predisposition syndromes appear to have a limited contribution to the occurrence of lower urinary tract urothelial carcinomas. $^{2}$

In adults, loss of heterozygosity of chromosome 9 and abnormalities of FGFR3 are characteristically associated with noninvasive papillary tumors, whereas mutation of the TP53 gene (17p13.1) is typical of urothelial carcinoma in situ, and highgrade and invasive carcinomas. ${ }^{23,43-45}$ In particular, mutations of FGFR3 have been reported in $72-84 \%$ of low-grade papillary urothelial carcinomas and $>70 \%$ of noninvasive papillary urothelial carcinomas. ${ }^{23-30}$ In general, the frequency of FGFR3 gene mutations appears to correlate inversely with increasing tumor grade and stage. ${ }^{23}$ As such, in high-grade and muscle-invasive bladder cancers, FGFR3 gene mutation has been noted in as little as $20-22 \%$. Conversely, the rate of mutation of the TP53 gene appears to increase from 7 to $11 \%$ in the lowest grade (previously considered grade 1) and noninvasive tumors to as high as $\sim 51-58 \%$ in highgrade and invasive tumors. ${ }^{23}$ Some overlap between these two molecular pathways has also been reported, with a smaller subgroup of tumors harboring mutation of both genes. ${ }^{46-48}$ In addition to TP53 and FGFR3, the roles of a wide array of other genes have begun to be elucidated in bladder cancer pathogenesis, including $R B 1, E R B B 2, F G F R 1, H R A S, K R A S$, NRAS, PI3KCA, AKT1, CCND1, CDKN2A, CTNNB1, MDM2, PTEN, TERT, and TSC1 with potential therapeutic targets. ${ }^{23,40,49-52}$ the chromosomal level, the UroVysion probe set was designed to target common chromosomal abnormalities in urothelial carcinomas, one of which includes deletion of CDKN2A (also known as p16), located at chromosome 9p21. ${ }^{53}$ Simultaneous utilization of four multicolored probes for other common chromosomal abnormalities (chromosomes 3, 7, and 17) has been found to improve the sensitivity of the assay, while remaining technically feasible for separate evaluation. ${ }^{19}$ The TP53 gene in particular is located on chromosome 17p13.1. Although the exact mechanisms by which these chromosomal gains and losses contribute to urothelial carcinogenesis are not entirely elaborated, other genes located at these sites that have been implicated in tumorigenesis include PIK3CA (chromosome 3q26.3), ERBB2 (17q11.2-q12), and CTNNB1 (3p21). ${ }^{49,52,54}$

Only a few studies have attempted to address the molecular pathogenesis of urothelial carcinomas of young patients. Linn et $a l^{12}$ examined a series of tumors from patients under age 30 years. Overall, numerical abnormalities of chromosomes 9 and 17 by in situ hybridization were uncommon. As the majority of the tumors were low stage and low grade, the lack of chromosome 9 abnormalities was surprising and contrasted with low-grade tumors of older adults. Aneuploidy of chromosome 17 was found in a smaller group of tumors, representing a comparatively large fraction of the invasive urothelial carcinomas and urothelial carcinoma in situ. Nuclear labeling for TP53 by immunohistochemistry was surprisingly common, including lowgrade, low-stage tumors that might not otherwise be expected to have TP53 gene mutation. However, mutation status of the TP53 gene itself was not evaluated. ${ }^{12}$

More recently, Wild et $a 1^{10}$ evaluated immunohistochemical and molecular characteristics in a series of urothelial tumors from patients 4-19 years of age. Using a wide array of molecular tests, relatively few abnormalities were identified. ${ }^{10}$ FGFR3 gene mutation and $9 p$ deletion in particular were absent, despite the predominant composition of the study set by low-grade tumors, similar to the findings of Linn et al. ${ }^{10,12}$ Arguing against the possibility that the high rate of positivity for TP53 by immunohistochemistry observed by Linn et al is the result of frequent mutation of the gene, only 1 of 14 tumors showed nonsense mutation in the TP53 gene and positive immunohistochemical labeling for TP53. ${ }^{10,12}$ Overall, the authors concluded that urothelial neoplasms in this age group are infrequently 
associated with the typical genetic alterations of urothelial carcinoma in older patients. ${ }^{10}$

A recent study by Owen et al ${ }^{11}$ examined epigenetic alterations in urothelial carcinomas stratified by age. The authors examined the same group of patients under age 19 years as analyzed by Wild et al. ${ }^{10}$ This youngest group had the lowest rates of promoter methylation for eight tumor suppressor genes involved in urothelial carcinogenesis. ${ }^{11}$ Interestingly, patients over 20 years of age had similar epigenetic profiles to those of the oldest patient group ( $>46$ years, median 78 ), suggesting that an age of $\sim 19-20$ years separates two genetically distinct groups of urothelial tumors. ${ }^{11}$

Supporting the hypothesis that urothelial carcinoma in young patients has a distinct molecular pathogenesis from that of older adults, we did not identify mutations of FGFR3 or TP53 in this study, despite the key roles of these gene mutations in urothelial carcinomas in general. In particular, the absence of FGFR3 gene mutation in the group of low-grade, noninvasive papillary urothelial carcinomas contrasts strikingly with the typical profile of these tumors from older adults, in which rates of FGFR3 gene mutation have been noted to be $>75 \% .{ }^{23}$ Although a relatively small number of tumors were considered high grade, complete absence of TP53 gene mutation in this subgroup also contrasts with high-grade tumors of older adults. We did, however, observe chromosome 9p21 loss as a sole abnormality in a subgroup of low-grade papillary urothelial carcinomas (2 of 17 tumors overall and 2 of 10 low-grade papillary urothelial carcinomas). In adults, loss of heterozygosity and deletion of this region are common events in urothelial carcinoma, thought to be an early event in carcinogenesis and associated with tumor recurrence. ${ }^{23,32,40,55-58}$ This region contains the gene $C D K N 2 A$ (also referred to as p16 or INK4a) that is thought to play an important role in the development of bladder cancer. ${ }^{59,60}$ Similar to the limited existing data in this population, ${ }^{10,12}$ our results suggest that this alteration is less common in young patients than in older adults, although our results do indicate that this aberration is occasionally present, particularly in patients above age 19 years. The UroVysion fluorescence in situ hybridization technique also includes chromosome enumeration probes directed to chromosomes 3, 7, and 17 , selected for the frequent alterations of these chromosomes in urothelial carcinomas. ${ }^{61,62}$ In contrast to loss of 9 p21 as a sole abnormality in some low-grade urothelial carcinomas, abnormalities of one or more of these other chromosomes were detected by UroVysion fluorescence in situ hybridization in exclusively high-grade tumors ( 3 of 17 tumors overall and 3 of 5 high-grade tumors). Similar to aberrations of 9p21, these abnormalities of chromosomes 3,7 , and 17 in high-grade tumors were also observed only in patients $\geq 19$ years of age. Interestingly, only one of these high-grade tumors exhibited a polysomic pattern (gain of two or more of the chromosomes in the probe set) that in adults is a common pattern for high-grade urothelial carcinoma. ${ }^{19}$ Further expanding the understanding of molecular pathogenesis of urothelial carcinoma in young patients and linking the results of Linn et al with those of Wild et al and Owen et al, our results support the idea that an age of $\sim 19-20$ years may separate two distinct pathways of urothelial carcinogenesis at the molecular level ('pediatric' patients and young adults). ${ }^{10-12}$ However, absence of FGFR3 and TP53 gene mutations, even in tumors from young adults, represents a point of contrast. Further investigation of tumors in these settings will be useful to better elucidate these differences, and whether other alterations, such as translocations, ${ }^{63}$ play a role in the development of urothelial carcinomas of pediatric patients.

In conclusion, urothelial neoplasms are rare in pediatric and young adult patients. When they do occur, it appears that their biologic behavior and molecular pathogenesis may be distinct from those of older patients. However, the molecular features of these tumors have previously been examined in only a few series. In this study, we analyzed molecular abnormalities in urothelial neoplasms from young patients below 30 years of age. We observed no mutations of the FGFR3 or TP53 genes, supporting the hypothesis that these abnormalities are rare in urothelial neoplasms of young patients. Although chromosomal abnormalities detected by UroVysion fluorescence in situ hybridization have been generally regarded as uncommon in urothelial neoplasms of young patients, we detected such abnormalities in a subgroup of cases, exclusively in patients $\geq 19$ years of age. Loss of chromosome 9p21 as a sole abnormality occurred in low-grade papillary noninvasive tumors, whereas gains or losses of other chromosomes were observed only in highgrade or invasive tumors. Our findings support the idea that distinct pathogenetic mechanisms may be involved in urothelial carcinogenesis particularly for patients under age 19 years, in whose tumors molecular abnormalities appear to be the most rare. In patients older than 19 years of age, chromosomal abnormalities detected by fluorescence in situ hybridization occasionally overlap with those of older adults.

\section{Disclosure/conflict of interest}

The authors declare no conflict of interest.

\section{References}

1 Cheng L, Lopez-Beltran A, Bostwick DG (eds). Bladder Pathology. Wiley-Blackwell: Hoboken, NJ, 2012.

2 Williamson SR, Lopez-Beltran A, MacLennan GT, et al. Unique clinicopathologic and molecular characteristics 
of urinary bladder tumors in children and young adults. Urol Oncol 2013;31:414-426.

3 Siegel R, Naishadham D, Jemal A. Cancer statistics, 2013. CA Cancer J Clin 2013;63:11-30.

4 Javadpour N, Mostofi FK. Primary epithelial tumors of the bladder in the first two decades of life. J Urol 1969; 101:706-710.

5 Benson RC Jr., Tomera KM, Kelalis PP. Transitional cell carcinoma of the bladder in children and adolescents. J Urol 1983;130:54-55.

6 Fine SW, Humphrey PA, Dehner LP, et al. Urothelial neoplasms in patients 20 years or younger: a clinicopathological analysis using the World Health Organization 2004 Bladder Consensus Classification. J Urol 2005;174:1976-1980.

7 McCarthy JP, Gavrell GJ, LeBlanc GA. Transitional cell carcinoma of bladder in patients under thirty years of age. Urology 1979;13:487-489.

8 Paduano L, Chiella E. Primary epithelial tumors of the bladder in children. J Urol 1988;139:794-795.

9 Stanton ML, Xiao L, Czerniak BA, et al. Urothelial tumors of the urinary bladder in young patients: a clinicopathologic study of 59 cases. Arch Pathol Lab Med 2013;137:1337-1341.

10 Wild PJ, Giedl J, Stoehr R, et al. Genomic aberrations are rare in urothelial neoplasms of patients 19 years or younger. J Pathol 2007;211:18-25.

11 Owen HC, Giedl J, Wild PJ, et al. Low frequency of epigenetic events in urothelial tumors in young patients. J Urol 2010;184:459-463.

12 Linn JF, Sesterhenn I, Mostofi FK, et al. The molecular characteristics of bladder cancer in young patients. J Urol 1998;159:1493-1496.

13 Eble JN, Sauter G, Epstein JI, Sesterhenn IA (eds). World Health Organization Classification of Tumours: Pathology and Genetics of Tumours of the Urinary System and Male Genital Organs. IARC Press: Lyon, 2004.

14 Appanna TC, Doak SH, Jenkins SA, et al. Comparative genomic hybridization (CGH) of augmentation cystoplasties. Int J Urol 2007;14:539-544.

15 Soergel TM, Cain MP, Misseri R, et al. Transitional cell carcinoma of the bladder following augmentation cystoplasty for the neuropathic bladder. J Urol 2004;172:1649-1651; discussion 51-2.

16 Sung MT, Zhang S, Lopez-Beltran A, et al. Urothelial carcinoma following augmentation cystoplasty: an aggressive variant with distinct clinicopathological characteristics and molecular genetic alterations. Histopathology 2009;55:161-173.

17 Williamson SR, Zhang S, Lopez-Beltran A, et al. Lymphoepithelioma-like carcinoma of the urinary bladder: clinicopathologic, immunohistochemical, and molecular features. Am J Surg Pathol 2011;35: 474-483.

18 Kipp BR, Tyner HL, Campion MB, et al. Chromosomal alterations detected by fluorescence in situ hybridization in urothelial carcinoma and rarer histologic variants of bladder cancer. Am J Clin Pathol 2008;130: 552-559.

19 Halling KC, Kipp BR. Bladder cancer detection using FISH (UroVysion assay). Adv Anat Pathol 2008;15: 279-286.

20 Schwarz S, Rechenmacher M, Filbeck T, et al. Value of multicolour fluorescence in situ hybridisation (UroVysion) in the differential diagnosis of flat urothelial lesions. J Clin Pathol 2008;61:272-277.
21 Lott S, Wang M, Zhang S, et al. FGFR3 and TP53 mutation analysis in inverted urothelial papilloma: incidence and etiological considerations. Mod Pathol 2009;22:627-632.

22 Armstrong $\mathrm{AB}$, Wang $\mathrm{M}$, Eble JN, et al. TP53 mutational analysis supports monoclonal origin of biphasic sarcomatoid urothelial carcinoma (carcinosarcoma) of the urinary bladder. Mod Pathol 2009; 22:113-118.

23 Cheng L, Zhang S, MacLennan GT, et al. Bladder cancer: translating molecular genetic insights into clinical practice. Hum Pathol 2011;42:455-481.

24 van Rhijn BW, Lurkin I, Radvanyi F, et al. The fibroblast growth factor receptor 3 (FGFR3) mutation is a strong indicator of superficial bladder cancer with low recurrence rate. Cancer Res 2001;61:1265-1268.

25 Kimura T, Suzuki H, Ohashi T, et al. The incidence of thanatophoric dysplasia mutations in FGFR3 gene is higher in low-grade or superficial bladder carcinomas. Cancer 2001;92:2555-2561.

26 Junker K, van Oers JM, Zwarthoff EC, et al. Fibroblast growth factor receptor 3 mutations in bladder tumors correlate with low frequency of chromosome alterations. Neoplasia 2008;10:1-7.

27 Burger $\mathrm{M}$, van der Aa $\mathrm{MN}$, van Oers JM, et al. Prediction of progression of non-muscle-invasive bladder cancer by WHO 1973 and 2004 grading and by FGFR3 mutation status: a prospective study. Eur Urol 2008;54:835-843.

28 Billerey C, Chopin D, Aubriot-Lorton $\mathrm{MH}$, et al. Frequent FGFR3 mutations in papillary non-invasive bladder (pTa) tumors. Am J Pathol 2001;158:1955-1959.

29 Bakkar AA, Wallerand H, Radvanyi F, et al. FGFR3 and TP53 gene mutations define two distinct pathways in urothelial cell carcinoma of the bladder. Cancer Res 2003;63:8108-8112.

30 Al-Ahmadie HA, Iyer G, Janakiraman M, et al. Somatic mutation of fibroblast growth factor receptor-3 (FGFR3) defines a distinct morphological subtype of high-grade urothelial carcinoma. J Pathol 2011;224:270-279.

31 Cheng L, Zhang S, Wang M, et al. Molecular genetic evidence supporting the neoplastic nature of stromal cells in 'fibrosis' after chemotherapy for testicular germ cell tumours. J Pathol 2007;213:65-71.

32 Cheng L, MacLennan GT, Zhang S, et al. Laser capture microdissection analysis reveals frequent allelic losses in papillary urothelial neoplasm of low malignant potential of the urinary bladder. Cancer 2004;101: 183-188.

33 Jebar AH, Hurst CD, Tomlinson DC, et al. FGFR3 and Ras gene mutations are mutually exclusive genetic events in urothelial cell carcinoma. Oncogene 2005;24:5218-5225.

34 Tomlinson DC, Baldo O, Harnden P, et al. FGFR3 protein expression and its relationship to mutation status and prognostic variables in bladder cancer. J Pathol 2007;213:91-98.

35 van der Sijp JR, van Meerbeeck JP, Maat AP, et al. Determination of the molecular relationship between multiple tumors within one patient is of clinical importance. J Clin Oncol 2002;20:1105-1114.

36 Vet JA, Bringuier PP, Schaafsma HE, et al. Comparison of P53 protein overexpression with P53 mutation in bladder cancer: clinical and biologic aspects. Lab Invest 1995;73:837-843.

37 Madgar I, Goldwasser B, Nativ O, et al. Long-term followup of patients less than 30 years old with 
transitional cell carcinoma of bladder. J Urol 1988; 139:933-934.

38 Androulakakis PA, Davaris P, Karayannis A, et al. Urothelial tumors of the bladder. Child Nephrol Urol 1992;12:32-34.

39 Yossepowitch O, Dalbagni G. Transitional cell carcinoma of the bladder in young adults: presentation, natural history and outcome. J Urol 2002;168:61-66.

40 Netto GJ. Clinical applications of recent molecular advances in urologic malignancies: no longer chasing a 'mirage'? Adv Anat Pathol 2013;20:175-203.

41 Zeegers MP, Kellen E, Buntinx F, et al. The association between smoking, beverage consumption, diet and bladder cancer: a systematic literature review. World J Urol 2004;21:392-401.

42 Johansson SL, Cohen SM. Epidemiology and etiology of bladder cancer. Semin Surg Oncol 1997;13:291-298.

43 Spruck CH 3rd, Ohneseit PF, Gonzalez-Zulueta M, et al. Two molecular pathways to transitional cell carcinoma of the bladder. Cancer Res 1994;54:784-788.

44 Cheng L, Zhang S, Davidson DD, et al. Molecular determinants of tumor recurrence in the urinary bladder. Future Oncol 2009;5:843-857.

45 Zieger K, Marcussen N, Borre M, et al. Consistent genomic alterations in carcinoma in situ of the urinary bladder confirm the presence of two major pathways in bladder cancer development. Int J Cancer 2009;125: 2095-2103.

46 Hernandez S, Lopez-Knowles E, Lloreta J, et al. FGFR3 and Tp53 mutations in T1G3 transitional bladder carcinomas: independent distribution and lack of association with prognosis. Clin Cancer Res 2005;11: 5444-5450.

47 Lindgren D, Liedberg F, Andersson A, et al. Molecular characterization of early-stage bladder carcinomas by expression profiles, FGFR3 mutation status, and loss of 9q. Oncogene 2006;25:2685-2696.

48 Zieger K, Dyrskjot L, Wiuf C, et al. Role of activating fibroblast growth factor receptor 3 mutations in the development of bladder tumors. Clin Cancer Res 2005;11:7709-7719.

49 Iyer G, Al-Ahmadie H, Schultz N, et al. Prevalence and co-occurrence of actionable genomic alterations in high-grade bladder cancer. J Clin Oncol 2013;31: 3133-3140.

50 Guo Y, Chekaluk Y, Zhang J, et al. TSC1 involvement in bladder cancer: diverse effects and therapeutic implications. J Pathol 2013;230:17-27.
51 Platt FM, Hurst CD, Taylor CF, et al. Spectrum of phosphatidylinositol 3-kinase pathway gene alterations in bladder cancer. Clin Cancer Res 2009;15: 6008-6017.

52 Lin C, Yin Y, Stemler K, et al. Constitutive beta-catenin activation induces male-specific tumorigenesis in the bladder urothelium. Cancer Res 2013;73:5914-5925.

53 Sokolova IA, Halling KC, Jenkins RB, et al. The development of a multitarget, multicolor fluorescence in situ hybridization assay for the detection of urothelial carcinoma in urine. J Mol Diagn 2000;2:116-123.

54 Ahmad I, Morton JP, Singh LB, et al. beta-Catenin activation synergizes with PTEN loss to cause bladder cancer formation. Oncogene 2011;30:178-189.

55 Cairns P, Shaw ME, Knowles MA. Initiation of bladder cancer may involve deletion of a tumour-suppressor gene on chromosome 9. Oncogene 1993;8:1083-1085.

56 Ruppert JM, Tokino K, Sidransky D. Evidence for two bladder cancer suppressor loci on human chromosome 9. Cancer Res 1993;53:5093-5095.

57 Kruger S, Mess F, Bohle A, et al. Numerical aberrations of chromosome 17 and the 9p21 locus are independent predictors of tumor recurrence in non-invasive transitional cell carcinoma of the urinary bladder. Int J Oncol 2003;23:41-48.

58 Bartoletti R, Cai T, Nesi G, et al. Loss of P16 expression and chromosome 9p21 LOH in predicting outcome of patients affected by superficial bladder cancer. J Surg Res 2007;143:422-427.

59 Orlow I, Lacombe L, Hannon GJ, et al. Deletion of the p16 and p15 genes in human bladder tumors. J Natl Cancer Inst 1995;87:1524-1529.

60 Orlow I, LaRue H, Osman I, et al. Deletions of the INK4A gene in superficial bladder tumors. Association with recurrence. Am J Pathol 1999;155:105-113.

61 Bubendorf L, Grilli B, Sauter G, et al. Multiprobe FISH for enhanced detection of bladder cancer in voided urine specimens and bladder washings. Am J Clin Pathol 2001;116:79-86.

62 Lokeshwar VB, Habuchi T, Grossman HB, et al. Bladder tumor markers beyond cytology: International Consensus Panel on bladder tumor markers. Urology 2005;66:35-63.

63 Scott AA, Stanley W, Worsham GF, et al. Aggressive bladder carcinoma in an adolescent. Report of a case with immunohistochemical, cytogenetic, and flow cytometric characterization. Am J Surg Pathol 1989; 13:1057-1063. 